\title{
MODELING AND SIMULATION OF MEMBRANE BIOREACTOR MODEL BASED ON ASM3 FOR DOMESTIC WASTEWATER TREATMENT
}

\author{
KAPUMBE, D. J. ${ }^{1}-$ Min, L. ${ }^{1}-$ ZHANG, X. ${ }^{1}-$ KisOHOLO, M. A. ${ }^{1}-$ YONGFENG, L. ${ }^{1 *}$ \\ ${ }^{1}$ School of Forestry, Northeast Forestry University, Harbin 150040, Heilongjiang, China \\ *Corresponding author \\ e-mail:dr_lyf@163.com; phone: +86-139-0361-4476 \\ (Received $18^{\text {th }}$ Apr 2019; accepted $11^{\text {th }}$ Jul 2019)
}

\begin{abstract}
Membrane bioreactor (MBR) is a water treatment system with a combination of the membrane separation unit and the bioreactor. The Activated Sludge Model (ASM) developed by the International Water Association offer a valuable instrument for designing, optimizing, and operation of the MBR. In this research, the MBR process based on the Activated Sludge Model No. 3 (ASM3) was compiled by the use of MATLAB/Simulink platform which can be applied to the water quality analysis of the MBR reactor effluent. The visual ASM3-MBR sewage processing simulation system was developed and had the advantages of an intuitive interface, clear meaning, easy data input, etc. After the model establishment, the division of model components, sensitivity analysis, and model calibration and verification, ASM3-MBR was amended and improved in this study.
\end{abstract}

Keywords: activated sludge, MATLAB/Simulink, modelling, water quality, separation unit

\section{Introduction}

The membrane bioreactor (MBR) is a system that combines biological treatment with membrane filtration into a single process. MBR is one of the most tent potent domestic/industrial wastewater treatment and reuse technologies currently $(\mathrm{Ng}$ and Kim, 2007). Also, this efficient and reliable technology has become a legitimate alternative to conventional activated sludge processes due to its perfect retention of biomass, pathogens removal, higher process performance and system stability (Castelo-Grande et al., 2010). The membrane bioreactors achieve perfect organics; chemical oxygen demand (COD), biochemical oxygen demand (BOD), and nutrient (nitrogen, phosphorus) removal as well as perfect retention of suspended solids.

Recently, MBR, especially submerged MBR, has been gaining a lot of attention for wastewater treatment in the aspects of high-quality effluent and a small footprint (Braak et al., 2011). The MBR process combines the biodegradation by the activated sludge process and the solid-liquid separation by the membrane filtration (Chang et al., 2006). It is, therefore, reasonable to use Activated Sludge Models to characterize the biomass dynamics in an MBR system. Mathematical modelling of MBR technology may help in providing insight into the factors that play a crucial role in the MBR process (Lee et al., 2002). At the same time, it can provide invaluable data for the design, forecast, and control of MBR technology.

Up to this day, mathematical model simulation of activated sludge processes have been used for the design of structures and control of operations in wastewater plants in most parts of the world. Since the publication of the first Activated Sludge Model (ASM) in 1986 (Liwarska-Bizukojc et al., 2011), the Activated Sludge Model No. 1 (ASM1) and its successors have become increasingly more popular. ASM1 was developed to model BOD and nitrogen removal, but it did not adequately describe all 
nutrients removal. Therefore Activated Sludge Model No. 2 (ASM2) was designed to incorporate biological nutrient removal of nitrogen and phosphorus (Gujer et al., 1995). However, ASM2 was far more complex, which created model operational difficulties. Activated Sludge Model No. 3 (ASM3) aimed to correct the defects of ASM1 and presented a new standard for ASM based modelling (Gujer et al., 1999).

The ASM3 model can effectively simulate the operation of the MBR. With the ASM3 model, the dimensions of various structures of the MBR are determined, and the appropriate process flow can be accurately selected. The key operating parameters of the MBR can also be predicted and determined; therefore, using the ASM3 model to simulate the MBR can optimize the operation and management of the MBR. The factors that affect the process of the MBR can be analyzed and evaluated.

Although the ASM series of models have gained widespread recognition from water treatment workers, due to the complexity of the model structure and parameters, it is still difficult to directly use them in reactor design, and many scholars are based on such models. At the expense of the universality of the model, many simplified models have been created, and proper monitoring and control results have been achieved. Using MATLAB/Simulink as the simulation software, the ASM3-based simulation of the MBR process can more intuitively reflect the effect of the reactor operation and can use the program to make a right prediction of the effluent outcome of the MBR (Gao et al., 2018).

Indeed, recently Li et al. (2009) applied a hybrid ASM model and showed the hybrid ASM model was calibrated and validated through a submerged MBR system under the reference condition. Mannina et al. (2011) presented an integrated MBR features and the calibration model protocol was illustrated with a pilot MBR plant in submerged configuration based on ASM1.

The major problem in the simulation of MBR is that the port has not been visualized. Only the programmers who are familiar with the structure can operate it flexible. Hence, through a concise and structured overview of past developments, this paper studied the effects of submerged MBR's wastewater treatment. This paper explored ASM3 based on modelling applied to MBR processes; ASM3 was chosen as the simulator and used the Simulink Toolbox in MATLAB7.0 to build a visual simulated program. The operation was done to predict the variation tendency of the effluent quality under the changing situation of inflow and outflow water quality when the reactor was in operation. This paper searches for the optimal operating parameters and will provide the basis for engineering design.

\section{Materials and methods}

\section{Experimental set-up}

An integrated MBR was used in the test. The test device diagram is shown in Figure 1. The temperature of the reactor 4 was adjusted to $25^{\circ} \mathrm{C}$ by the heater 7,5 is a hollow fiber membrane module, and the membrane material was polyacrylamide, hollow fiber filament. The diameter was about $0.6 \mathrm{~mm}$, the inner diameter was about $0.3 \mathrm{~mm}$, the membrane pore size was $0.05 \mu \mathrm{m}$, the length of the membrane module was $0.5 \mathrm{~m}$, the membrane molecular weight cut-off was 10000 Dalton, and the surface area of the membrane was $1 \mathrm{~m}^{2}$. The device used a micro-porous aerator for aeration, and the amount of aeration can be adjusted by the air flow meter 3 . The liquid level of the reactor was controlled by the balance tank. The float valve automatically controls the 
liquid level with the flow rate of the discharge water. With the change of the flow rate of the discharge water, the float valve was automatically controlled to maintain the balance between the discharge flow and the inflow. The hydrodynamic power was provided by the net head pressure difference. After the new membrane was placed in the reactor, water was pumped out using a glass water injector. The reactor had a sufficient volume of $18 \mathrm{~L}$. The aeration intensity of the device was very large, dissolved oxygen (DO) was maintained at about $8 \mathrm{mg} / \mathrm{L}$. After the commissioning operation was stable, the HRT of the control system was $5 \mathrm{~h}$, during which no sludge was discharged. When the system was operating stably, the concentration of incoming and outgoing water was measured.

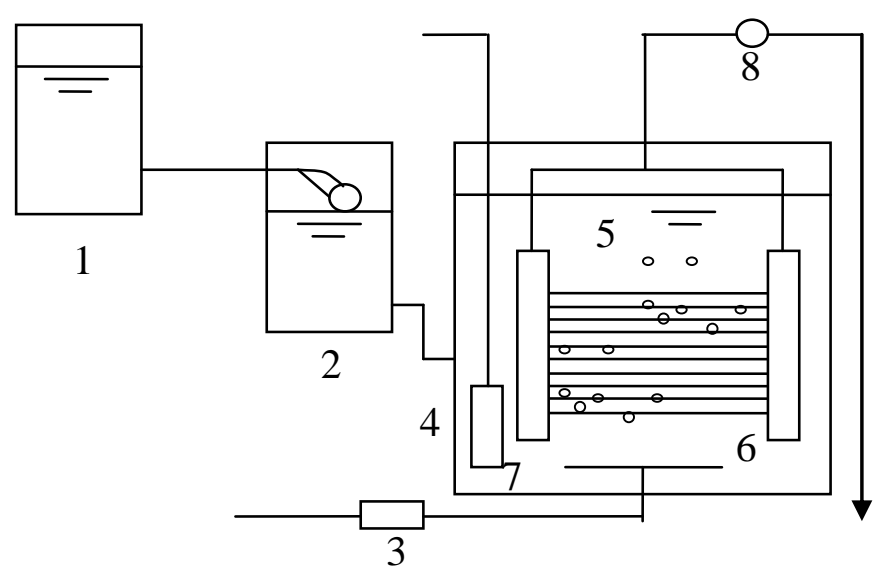

Figure 1. Schematic diagram of the test. (1 elevated tank, 2 balance tank, 3 air flow meter, 4 reactor, 5 hollow fiber membrane, 6 aeration device, 7 heater, 8 vacuum table)

\section{Mass balance and removal rates}

The biological reaction rate of a component $(i)$, at the time $(t), r_{i}$ was obtained according to the following equation (Mannina et al., 2011):

$$
r_{i}=\sum_{j} v_{i j} \rho_{j}
$$

Where $v$ is the stoichiometric matrix, $\rho$ is the kinetic rate, $i$ and $j$ are respectively the state variables and the biological processes. Meanwhile, the differential equations for all state variables were obtained from Equations 2, 3 and 4 by the mass balance:

$$
\begin{gathered}
\frac{d S_{i}}{d_{t}}=\frac{Q_{i n} S_{i, 0}-Q_{o} S_{i}+Q_{w} S_{i}}{V}+r_{i} \\
\frac{d X_{i}}{d t}=\frac{Q_{i n} X_{i, 0}-Q_{w} X_{i}}{V}+r_{i} \\
Q_{o}=Q f
\end{gathered}
$$


where $Q_{i n}$ is the influent flow-rate, $Q_{o}$ is the effluent flow-rate, $Q_{w}$ is the wasted sludge flow-rate, $V$ is the volume of the MBR $S_{i, 0}$ and $S_{i}$ are the concentration of soluble substrates in the influent and supernatant respectively, $X_{i, 0}$ and $X_{i}$ are the concentration of particulate substrate in the influent and reactor, respectively, $f$ is the coefficient of membrane interception.

In consideration of the heterotrophic bacteria and nitrifying bacteria in water in an amount negligible, these two components of this differential equation are simplified:

$$
\begin{aligned}
\frac{d X_{H}}{d t} & =r_{H} \\
\frac{d X_{A}}{d t} & =r_{A}
\end{aligned}
$$

The purpose of the sensitivity analysis of the model parameters was to study the influence of the size of the model parameter's error on the system's prediction (Wang et al., 2016). In the simulation, those parameters with higher sensitivity in the model need to be corrected. For parameters with lower sensitivity, the typical default values given by ASM3 can be directly used for simulation.

The sensitivity analysis method was used to analyze the simulated results of the ASM3-MBR model, and the dynamic parameter values and stoichiometric coefficients in the model were increased by $10 \%$ based on initial costs (Lee et al., 2002) and changed under the condition of keeping other parameters unchanged. The sensitivity value of a parameter was calculated according to the equation below:

$$
\sigma_{j, i}=\frac{\frac{C_{i, 1}-C_{i, 0}}{C_{i, 0}}}{\frac{\tau_{j, 1}-\tau_{j, 0}}{\tau_{j, 0}}}=\frac{\frac{\Delta C_{i}}{C_{i, 0}}}{\frac{\Delta \tau_{j}}{\tau_{j, 0}}}
$$

Where $\tau_{j, 0}$ is the initial value of the parameter, $\tau_{j, 1}$ is the parameter values after the change, $C_{i, 0}$ and $C_{i, 1}$ are a concentration of effluent indicator before and after the parameter change indicator. After an increase of $10 \%$ based on the initial values, the corresponding sensitivity values of parameters are positive and negative points. The positive value indicates that the increase of the parameter makes the effluent concentration of the component rise, and the negative value indicates that the increase of the parameter causes the effluent concentration of the component to decrease.

\section{Modelling}

The simulated program establishes its flow chart based on the parameter of the integrated MBR technology and design. ASM3 was chosen as a simulator, and the Simulink Toolbox in MATLAB7.0 was used to build a visual simulated program. The simulation model includes an influent module, the reaction module, and effluent combination module. The reaction module processing corresponding reactions, the 
influent module will feed components distribution in 13 kinds of parts according to specific rules. And effluent combination module is just the opposite; it is a combination of 13 types of component indicators need to detect the effluent, such as COD, Ammonia, total nitrogen (TN), as the basis for process analysis.

The establishment of the model starts with the basic sub-processes rate equation. The other components of the reaction rate equation are built by the mathematical operation. One or several parts of the kinetic equation can be used to describe a sub-process.

In the established model system, all the 13 sub-process can be built with the process. The basic rate equation is multiplied by a sub-process component in a stoichiometric coefficient of the sub-process. The sum of the parts in each sub-process of the reaction rate is the component of the total reaction rate of all sub-processes in which it participates. Such as $X_{I}$ generated in the sub-process 6, 7,11, and 12; therefore, $X_{I}$ 's total kinetic equation for the four sub-process reaction rate sums. We have:

$$
\left(d X_{I} / d_{t}\right)_{T}=f_{I}\left[\left(d X_{I} / d_{t}\right)_{6}+\left(d X_{I} / d_{t}\right)_{7}+\left(d X_{I} / d_{t}\right)_{11}+\left(d X_{I} / d_{t}\right)_{12}\right]
$$

In the MBR, a component of the quality in total rate equation of the ASM3 is the total reaction rate equation and the "one into one out" sum.

To $X_{I}$, for example, the total rate equation is:

$$
\frac{d X_{I}}{d_{t}}=\frac{Q_{i n} X_{I, 0}-Q_{o} X_{I}}{V} \pm \sum\left(\frac{d X_{I}}{d_{t}}\right)_{R}
$$

According to the method, the 13 component of the ASM3 corresponding model $\left(\mathrm{S}_{\mathrm{O} 2}\right.$, $\mathrm{S}_{\mathrm{I}}, \mathrm{S}_{\mathrm{S}}, \mathrm{S}_{\mathrm{NH} 2}, \mathrm{~S}_{\mathrm{N} 2}, \mathrm{~S}_{\mathrm{NOX}}, \mathrm{S}_{\mathrm{ALK}}, \mathrm{X}_{\mathrm{I}}, \mathrm{X}_{\mathrm{S}}, \mathrm{X}_{\mathrm{H}}, \mathrm{X}_{\mathrm{STO}}, \mathrm{X}_{\mathrm{A}}$ and $\mathrm{X}_{\mathrm{SS}}$ ) is established, and finally the simultaneous integration and then encapsulated.

After the model package, can be entered ASM3 as parameters in the parameter input box, these parameters can be adjusted as needed. In the first time of simulation, the input is the default reference values given by the International Water Association (IWA).

Data conversion is an essential factor in the model simulations. The data conversion floor is the measured data to the component data of ASM3 model transform process. Because the actual test data is not entirely of model constituents and therefore fall under the restriction of various conditions, it is difficult to measure constituents by using experiment. Hence, this concerns the problem of how to transform data into the model. This step is essential, whether the transformation is appropriate or not directly determines the success of the application of the model. In this test, the value influent COD, total nitrogen (TN), and ammonia were measured.

Finally, a visual interface of the ASM3-MBR was established. Simulated program debugs through static data, first carries out a sensitivity analysis for the model parameter and then corrects the parameter, control the error between system prediction's result and the actual measured results of the water within $5 \%$.

Figure 2 shows the simulation program of ASM3-MBR where TCOD represents the total influent COD, $\mathrm{V}$ represents the reactor volume, HRT represents hydraulic retention time, $Q_{w}$ is the wasted sludge flow-rate, $\mathrm{SNH} 4,0$ represents the influent ammonia content, SN2, 0 represents the total influent nitrogen, TN means influent TN content, 
SALK, 0 represents influent alkalinity, XSS, 0 indicates influent suspended solids content. After clicking the left of each window to run the input data can be observed on the right side of each window after the simulation of COD, ammonia nitrogen, TN results.

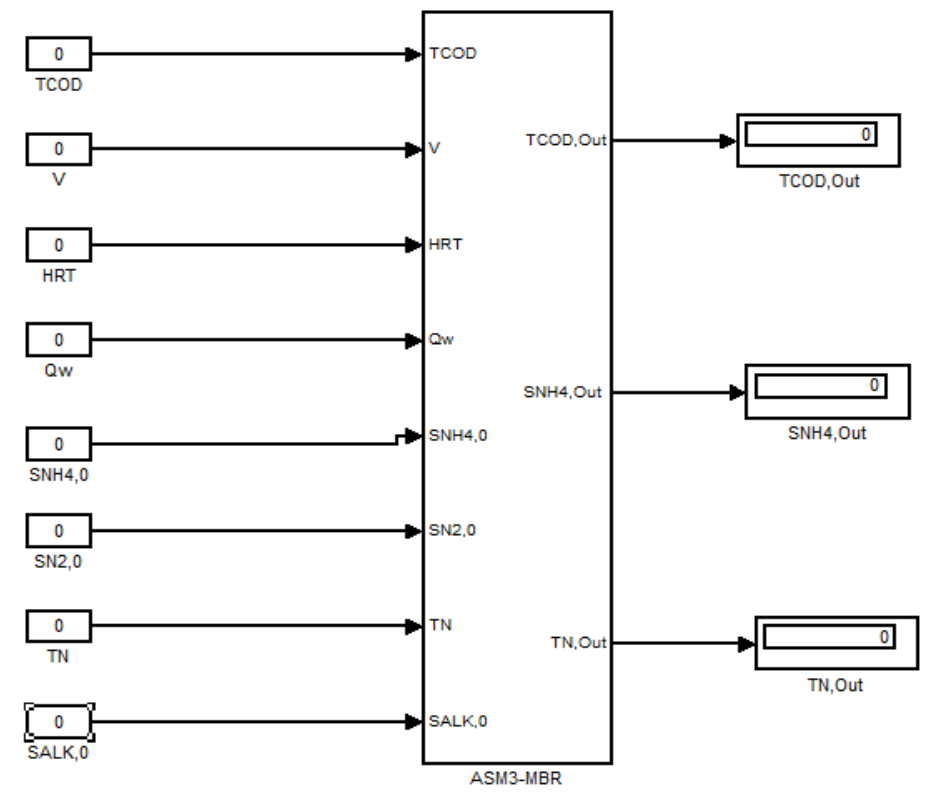

Figure 2. The simulation program of ASM3-MBR

The bottom floor of the simulation program is the basic rate equation. The second floor is the encapsulation of the relevant rate equations. The third floor is the encapsulation of a component of the overall reaction rate equation package. The fourth floor is the encapsulation of the integral simultaneous component of the total rate equation. The fifth floor is the input floor of the ASM3 model parameters, is the encapsulation of the entire rate equation integration module, parameter module, initial of points, and influent quality. Enter ASM3 typical kinetic parameter values. The simulation program uses the International Water Association (IWA) recommended default value $\left(20^{\circ} \mathrm{C}\right)$ (Henze et al., 2000).

\section{Results and discussion}

\section{Sensitivity analysis}

According to Equation 7, Table 1 shows ASM3 model sensitivity analysis results. From the parameter sensitivity analysis in Table 1 we can see that:

1. Some parameters have almost no effect on all the simulation results, such as the yield in the endogenous respiration, the rate of hypoxia based respiration, and the significant influence on the simulation results, such as the ratio of the hydrolysates, the maximum rate of growth. For these parameters with high sensitivity, parameter correction must be carried out in the simulation process to meet the precision requirements of the model. For the parameters with low sensitivity, the parameters cannot be corrected in the simulation, and the typical default values of the ASM3 model can be used directly. 
2. The higher sensitivity of the effluent COD simulation value to the parameter change from high to low is proportion in the hydrolysate, hydrolysis saturation constant, hydrolysis rate constant, aerobic yield per unit stock, aerobic endogenous respiration rate, the aerobic yield of heterotrophic bacteria, maximum specific growth rate.

3. The higher sensitivity of the effluent $\mathrm{NH}_{3}-\mathrm{N}$ simulation value to the parameter change from high to low is: the maximum specific growth rate, the ammonia nitrogen saturation coefficient, the aerobic endogenous respiration rate, the aerobic yield of heterotrophic bacteria, the aerobic yield, the maximum specific growth rate, and the saturation constant for the unit stock.

4. The higher sensitivity of the effluent $\mathrm{TN}$ simulation value to the parameter change is from the highest to the lowest: the unit nitrate yield, aerobic endogenous respiration rate, heterotrophic aerobic yield, and unit stock aerobic yield, maximum specific growth rate, hydrolysis saturation constant, storage rate regular.

\section{Parameter calibration}

The sensitivity analysis method is used to adjust the parameters with high sensitivity, and some settings with low sensitivity are set according to reference or typical values. The model parameter correction is performed on the MATLAB/Simulink platform. The differential equations involved in the model are solved in MATLAB using the established ASM3-MBR model (Song et al., 2012). After studying most of the literature, it was discovered that the process of correcting the model using data from dynamic inflows requires more computational time than static influx, and it has been proved in practice that static influent water is used to simulate the resulting information of the system (Bournazou et al., 2010). It will not be less than that obtained when using dynamic flood simulation (Wang et al., 2016). Therefore, the average value of the actual inlet and outlet water and water quality characteristics of the integrated MBR is used as the steady-state inlet and outlet water values to correct the parameters of the ASM3MBR model. Because of the average water value, the parameters that make the relative residual difference between the benefits of the simulated values of $\mathrm{COD}, \mathrm{NH}_{3}-\mathrm{N}, \mathrm{TN}$, and the measured values are minimal.

In the process of model calibration, the following principles need to be followed:

1. Most parameters should not be changed during the calibration process.

2. For each correction, only one parameter is changed. This is because there are usually substantial interactions between parameters in the model, so it is difficult to estimate the combined effects of several parameters, and changing multiple parameters during correction can lead to difficulties in calibration. Therefore, for the two parameters of the interaction, only the one that has a high more significant influence on the simulation result can be changed.

3. If the sensitivity of a parameter is low, this parameter does not need to be modified. However, if for some reason, the parameter must be modified, it must be adjusted according to the logic operation rules.

The model correction mainly adjusts the following four parameters: $f_{S I}$ adjusted to $0.45, \mu_{A}$ adjusted to $0.8, Y_{A}$ adjusted to $0.27, k_{H}$ adjusted to 3.1 . Other parameters 
were fine-tuned only for those with relatively high sensitivity. Simulation results after adjustment parameters are shown in Table 2.

Table 1. ASM3 model sensitivity analysis results

\begin{tabular}{|c|c|c|c|c|}
\hline \multirow{2}{*}{ Symbol } & \multirow{2}{*}{ Characterization } & \multicolumn{3}{|c|}{ Sensitivity } \\
\hline & & COD & Ammonia & TN \\
\hline$k_{H}$ & Hydrolysis rate constant & -0.1116 & -0.0008 & 0.0373 \\
\hline$K_{X}$ & Hydrolysis saturation constant & 0.1302 & -0.0649 & 0.1056 \\
\hline$k_{\text {STO }}$ & Storage rate constant & 0.0009 & -0.0852 & 0.0994 \\
\hline$\eta_{N O_{x}}$ & Anoxic reduction factor & 0.0009 & -0.0325 & 0.0373 \\
\hline$K_{O_{2}}$ & Saturation constant for $S_{\mathrm{O}_{2}}$ & 0.0009 & -0.073 & 0.0186 \\
\hline$K_{N O_{x}}$ & Saturation constant for $S_{N O_{x}}$ & 0.0009 & -0.0892 & 0.0373 \\
\hline$K_{S}$ & Saturation constant for substrate SS $S_{S}$ & 0.0009 & -0.0243 & 0.0248 \\
\hline$K_{S T O}$ & Saturation constant for $X_{S T O}$ & -0.0009 & -0.0122 & 0.0186 \\
\hline$\mu_{H}$ & Maximum specific growth rate of $X_{H}$ & 0.0279 & -0.1095 & 0.1304 \\
\hline$K_{N_{4}}$ & Saturation constant for ammonium, $S_{\mathrm{NH}_{4}}$ & 0.0009 & -0.0284 & 0.0373 \\
\hline$K_{A L K}$ & Alkalinity saturation constant for $X_{H}$ & 0.0009 & -0.0284 & 0.0373 \\
\hline$b_{H, O_{2}}$ & Aerobic endogenous respiration rate for $X_{H}$ & 0.0372 & -0.0365 & 0.2547 \\
\hline$b_{H, N O_{x}}$ & Anoxic endogenous respiration rate for $X_{H}$ & 0.0009 & -0.0243 & 0.0373 \\
\hline$b_{\text {STO, } O_{2}}$ & Aerobic respiration rate of $X_{\text {STO }}$ & 0 & -0.0446 & 0.0559 \\
\hline$b_{S T O, N O_{x}}$ & Anoxic respiration rate for $X_{S T O}$ & 0 & -0.0162 & 0.0248 \\
\hline$\mu_{A}$ & Maximum specific growth rate of $X_{A}$ & 0 & -1.144 & 0.0311 \\
\hline$K_{A, N H_{4}}$ & Ammonium substrate saturation for $X_{A}$ & 0.0009 & 0.9736 & 0.0373 \\
\hline$K_{A, O_{2}}$ & Oxygen saturation for nitrifiers & 0.0009 & -0.0892 & 0.0373 \\
\hline$K_{A, A L K}$ & Bicarbonate saturation for nitrifiers & 0.0009 & 0.0649 & 0.0373 \\
\hline$b_{A, O_{2}}$ & Aerobic endogenous respiration rate of $X_{A}$ & 0.0009 & 0.7911 & 0.0497 \\
\hline$b_{A, N O_{x}}$ & Anoxic endogenous respiration rate of $X_{A}$ & 0.0009 & -0.0365 & 0.0435 \\
\hline$f_{S I}$ & Production of $S_{I}$ in Hydrolysis & 0.1571 & 0 & 0.0123 \\
\hline$Y_{S T O, O_{2}}$ & The aerobic yield of stored product per $S_{S}$ & 0.0465 & 0.1095 & -0.1925 \\
\hline$Y_{S T O, N O_{x}}$ & The anoxic yield of stored product per $S_{S}$ & 0.0009 & -0.0406 & 0.0373 \\
\hline$Y_{H, O_{2}}$ & Aerobic yield of heterotrophic biomass & 0.0372 & 0.1136 & -0.1988 \\
\hline$Y_{H, N O_{x}}$ & Anoxic yield of heterotrophic biomass & 0.0009 & -0.0284 & 0.0311 \\
\hline$Y_{A}$ & Yield of autotrophic biomass per $\mathrm{NO}_{3}-\mathrm{N}$ & 0.0009 & -0.0649 & -1.5217 \\
\hline$f_{X_{I}}$ & Endogenous respiration in the yield & 0 & 0 & 0 \\
\hline
\end{tabular}


Table 2. Simulation results after adjustment parameters

\begin{tabular}{c|c|c|c}
\hline Constituent & COD & Ammonia & TN \\
\hline The average of influent & 460.29 & 19.71 & 20.6 \\
Measured value of effluent & 17.62 & 0.31 & 11.97 \\
Typical simulation results & 24.29 & 0.2465 & 15.27 \\
Simulation results of parameter correction & 17.74 & 0.3118 & 11.94 \\
Typical error of simulation results & $3.79 \%$ & $20.48 \%$ & $37.57 \%$ \\
Correction parameter of simulation results & $0.07 \%$ & $0.06 \%$ & $0.03 \%$ \\
\hline
\end{tabular}

It can be seen from Table 2 that the error of the simulated values of the effluent $\mathrm{COD}, \mathrm{NH}_{3}-\mathrm{N}$, and $\mathrm{TN}$ after correction is $0.07 \%, 0.06 \%$, and $0.03 \%$ respectively. The simulated values are in good agreement with the measured values, and the simulation is ideal. Therefore, the validated ASM3-MBR model can be used to simulate and predict the effluent index of the reactor.

Zhou et al. (2013) in their research reported that the simulated results fitted very well with the experimental data. After 30 days of simulation, the fluctuations in effluent COD concentrations over the intervals were less than $0.3 \%$. The goodness of fit of the COD between the measured and simulated values was $99.7 \%$. The difference between the simulated and measured $\mathrm{NH}_{4}-\mathrm{N}$ values was less than $0.8 \%$, implying a right model prediction for ammonia removal. Overall, the modified ASM3 model obtained a right first prediction concerning the long-term behaviour of effluent COD and $\mathrm{NH}_{4}-\mathrm{N}$ concentrations. Also, Blomberg et al. (2018) observed that the ammonia oxidation was directly linked to all of the main nitrogen conversion reactions in the activated sludge process (ASP). The model was able to reproduce the measured $\mathrm{NH}_{4}$ peaks in the effluent of the ASP throughout the simulation. During the calibration period, the modelled peaks were able to reach the measured values throughout the simulation. Consistently, the model was able to reproduce the measured peaks during the validation phase. Elawwad et al. (2017) reported that the ASM3 provided good representation for WWTP performance. The modelled effluent COD was consistent with the measured COD values.

\section{Comparison of simulation results of ASM3 model under different influent water quality}

The MBR reactor in this test did not discharge mud during the test. The sludge concentration in the reactor was about $2000 \mathrm{mg} / \mathrm{L}$ when the device was started. The temperature of the reactor was maintained at $24{ }^{\circ} \mathrm{C}$ and the hydraulic retention time was $5 \mathrm{~h}$ during operation, the aeration intensity was maintained at a relatively broad level to ensure the dissolved oxygen concentration in the reactor fully. The DO was maintained at about $8 \mathrm{mg} / \mathrm{L}$.

The measured and simulated values of the integrated MBR effluent COD and the residual analysis diagram are shown in Figures 3 and 4.

From Figures 3 and 4, it can be seen that the integrated MBR has a good removal effect on the COD, the effluent COD was very low, and the total COD removal rate was high. The overall impact of the ASM3-MBR model on the simulation of COD effluent was good, except for some points, the simulation values and the measured values were in good agreement. After calculation, the simulated relative error of COD was from 
0.46 to $23.66 \%$, and the average relative error was $3.88 \%$. Wu et al. (2016) observed an average absolute relative error between the measured and simulated values of $16.8 \%$ for the COD effluent while simulating and optimizing a practical cooking wastewater treatment plant (CWTP). Their results revealed that the ASM3 model had been successfully established to simulate the biological process of the CWTP.

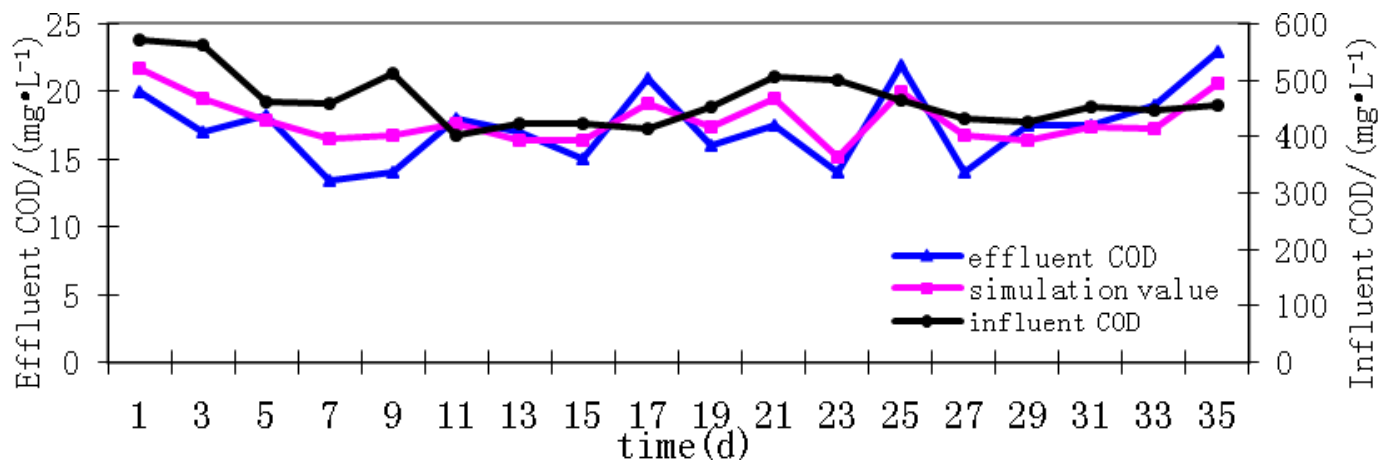

Figure 3. The measured and simulated values of the integrated MBR effluent COD

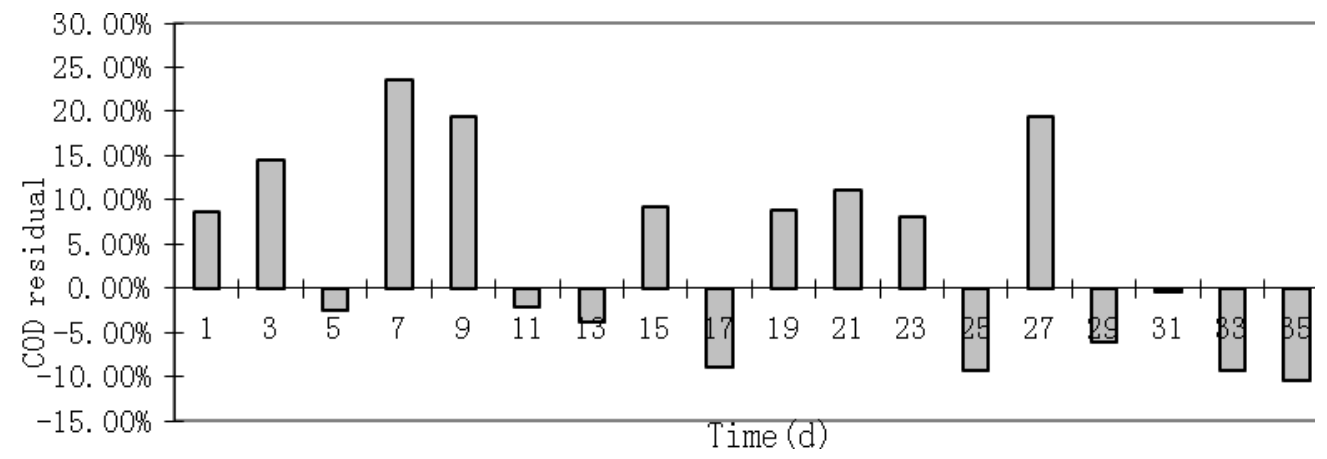

Figure 4. The residual analysis diagram of the integrated MBR effluent COD.

The measured and simulated values of the integrated $\mathrm{MBR}$ effluent $\mathrm{NH}_{3}-\mathrm{N}$ and the residual analysis diagram are shown in Figures 5 and 6.

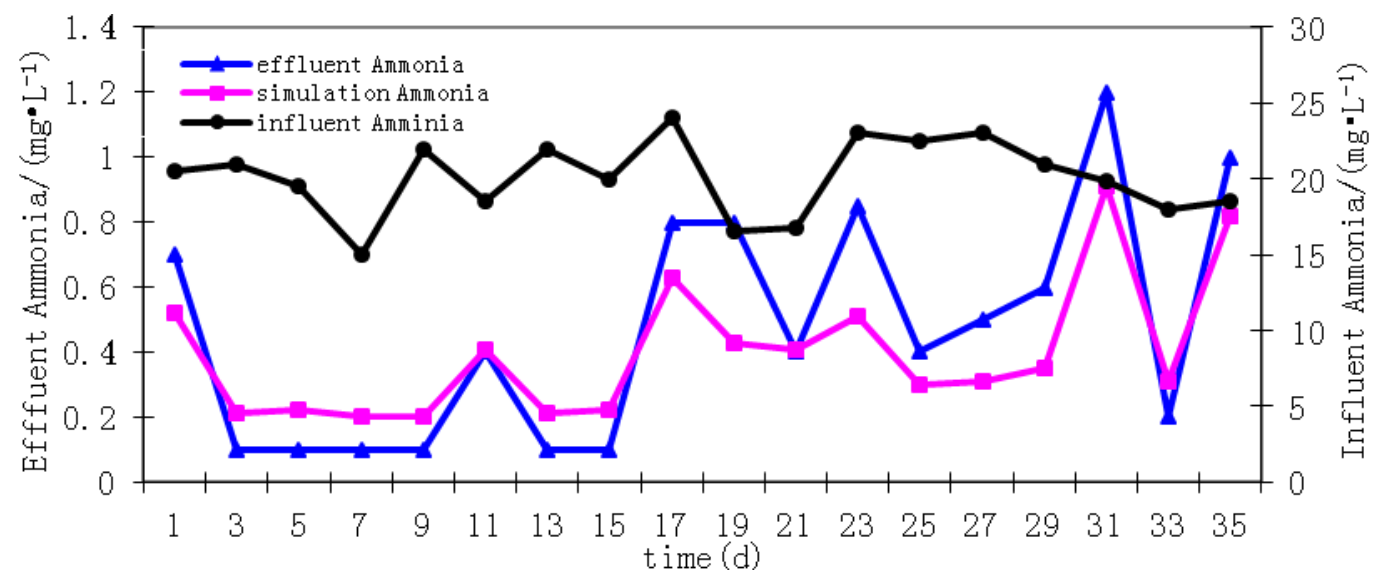

Figure 5. The measured and simulated values of the integrated MBR effluent $\mathrm{NH}_{3}-\mathrm{N}$ 


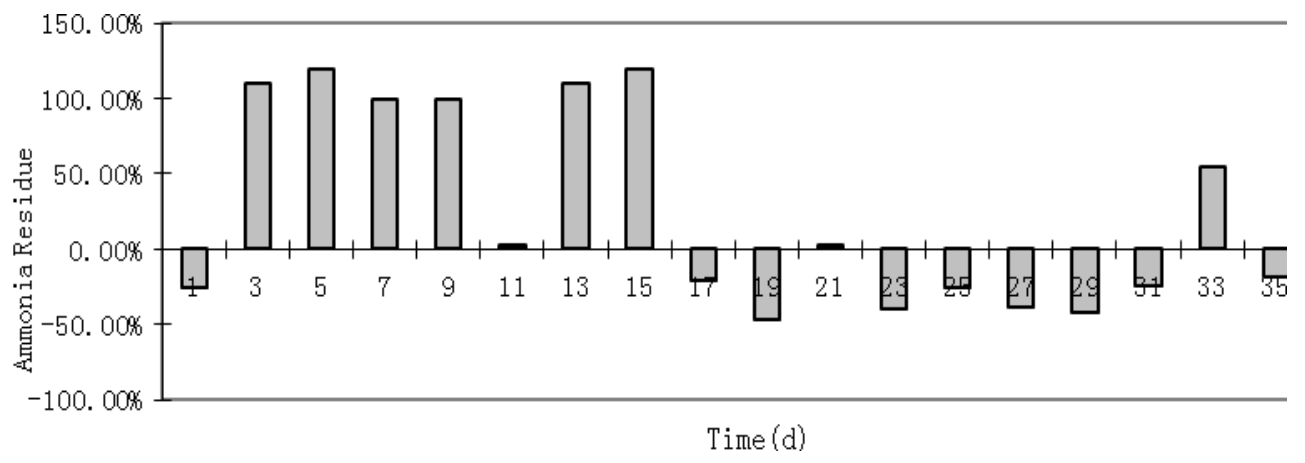

Figure 6. The residual analysis diagram of the integrated $\mathrm{MBR}$ effluent $\mathrm{NH}_{3}-\mathrm{N}$

As seen in Figure 5, the integrated MBR process worked well with $\mathrm{NH}_{3}-\mathrm{N}$. In $\mathrm{MBR}$, since the correlation between the influent $\mathrm{NH}_{3}-\mathrm{N}$ value and the effluent $\mathrm{NH}_{3}-\mathrm{N}$ value was relatively weak, the simulated value of the effluent $\mathrm{NH}_{3}-\mathrm{N}$ during the simulation of the ASM3 model was between the $\mathrm{NH}_{3}-\mathrm{N}$ values of the influent. There is a close correlation. Therefore, when using the ASM3-MBR model established based on ASM3 to simulate MBR, there will be some errors between the effluent $\mathrm{NH}_{3}-\mathrm{N}$ simulated value and the effluent $\mathrm{NH}_{3}-\mathrm{N}$ measured value. However, because the concentration of $\mathrm{NH}_{3}-\mathrm{N}$ in the effluent was deficient, and the effluent standard was fully met, and the prediction of total effluent nitrogen was not substantially affected, the prediction could be considered as reasonable. From Figures 5 and 6 , the relative error of $\mathrm{NH}_{3}-\mathrm{N}$ simulation was from 2.5 to $120 \%$, and the average relative error was about $24.44 \%$. However, $\mathrm{Wu}$ et al. (2016) observed an average absolute relative error between the measured and simulated values of $15 \%$ for $\mathrm{NH}_{4}-\mathrm{N}$ effluent and a good agreement in the benefits from the model prediction, and practical measurement was observed.

Figures 7 and 8 show the measured and simulated values of the integrated MBR effluent TN and the residual analysis diagram of the integrated MBR effluent TN.

From Figures 7 and 8, the overall effect of the ASM3-MBR model for effluent simulation of TN was good, except for some points, the simulation values and the measured values were in good agreement. After calculation, the relative error of TN simulation was from 0.18 to $27.43 \%$, and the average relative error was $5.39 \%$.

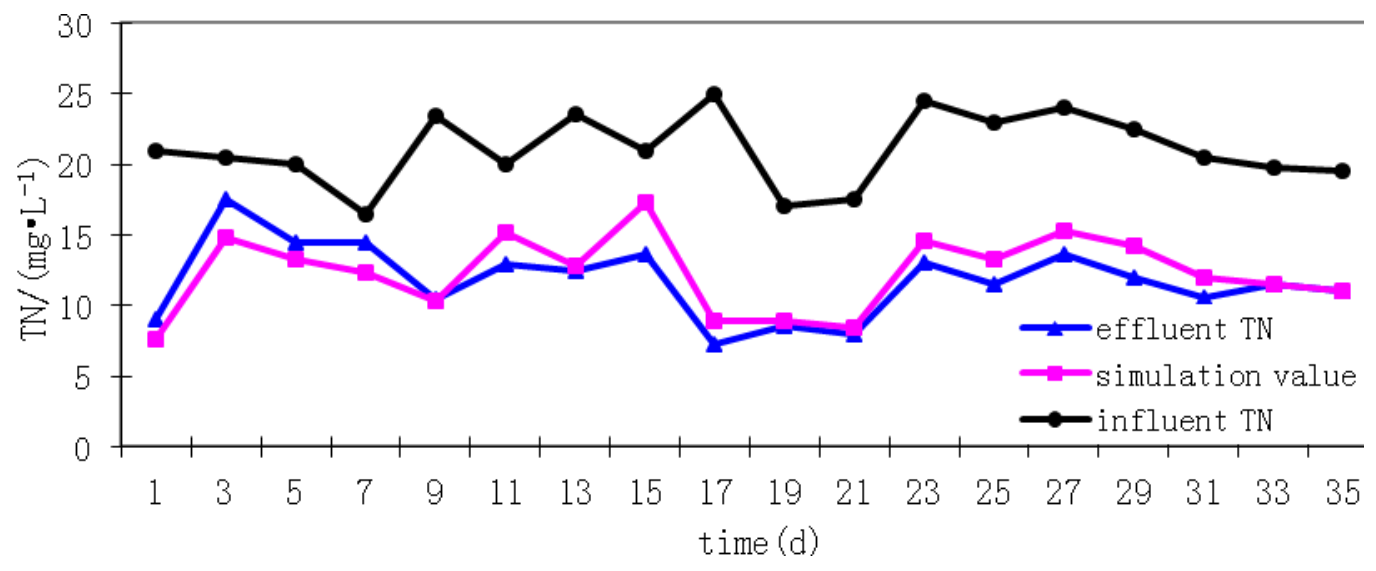

Figure 7. The measured and simulated values of the integrated MBR effluent TN 


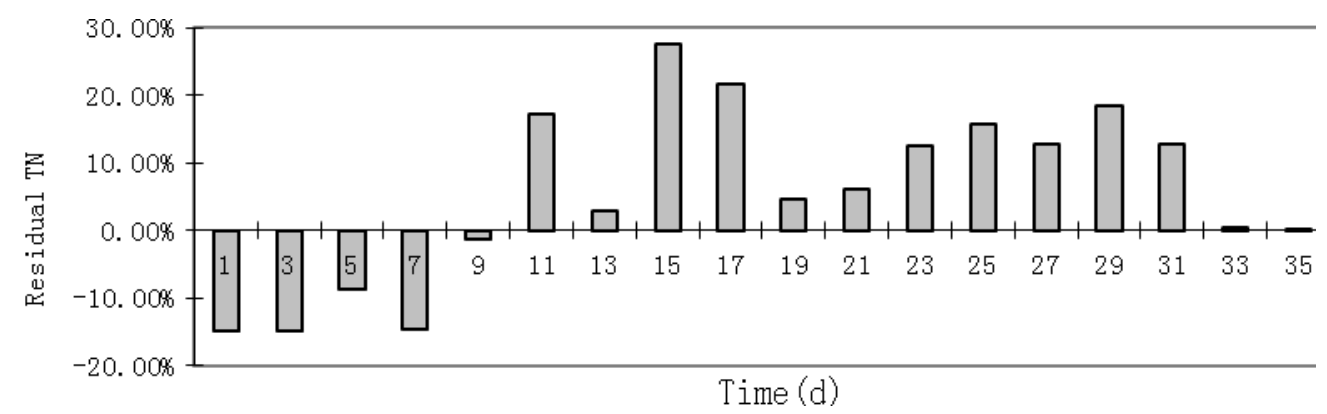

Figure 8. The residual analysis diagram of the integrated MBR effluent TN

\section{Conclusion}

In this research, the established ASM3-MBR model simulation system was used to simulate the steady-state and dynamics of the integrated MBR. The simulation results of the ASM3-MBR model for the effluent $\mathrm{COD}, \mathrm{NH}_{3}-\mathrm{N}$, and $\mathrm{TN}$ were analyzed. In general, the self-developed simulation system was more consistent with the simulated and measured values of the effluent COD and TN of the MBR system, thus validating the effectiveness and practicality of the ASM3-MBR model. The simulation results also showed that the error between the simulated value and the measured value was unavoidable. The ASM3-MBR model can more accurately simulate the treatment effect of the integrated MBR and the changing rules of various pollutants. This has a significant supporting role in understanding the contaminant removal mechanism of the integrated MBR, optimizing the operational control of the reactor, and predicting the outflow indicators.

It can be concluded that, a precise adjustment and optimization of the simulation program ASM3-MBR can be used to predict the effluent quality of the MBR process sewage treatment plant, and the operation management of the sewage treatment plant can be optimized. More research is, however, required to optimize ASM3-MBR model performance, especially the effluent quality, and reduction of error between the simulated value and the measured value.

This optimization will make ASM3-MBR model more attractive for use as a preferred remediation strategy in wastewater treatment, considering the significant of contaminant removal mechanism of the integrated MBR.

Acknowledgements. This research has been supported by the Heilongjiang Province Natural Science Foundation of China (E201354).

\section{REFERENCES}

[1] Blomberg, K., Kosse, P., Mikola, A., Kuokkanen, A., Fred, T., Heinonen, M., Mulas, M., Lübken, M., Wichern, M., Vahala, R. (2018): Development of an extended ASM3 model for predicting the nitrous oxide emissions in a full-scale wastewater treatment plant. Environmental Science \& Technology 52(10): 5803-5811.

[2] Bournazou, M. C., Arellano-Garcia, H., Wozny, G., Lyberatos, G., Kravaris, C. (2010): Model reduction of the ASM3 extended for two-step nitrification. - IFAC Proceedings 43(6): 60-65. 
[3] Braak, E., Alliet, M., Schetrite, S., Albasi, C. (2011): Aeration and hydrodynamics in submerged membrane bioreactors. - Journal of Membrane Science 379(1-2): 1-18.

[4] Castelo-Grande, T., Augusto, P. A., Monteiro, P., Barbosa, D. (2010): Design and application of a membrane bioreactor unit to upgrade and enhance the required performance of an installed wastewater treatment plant. - Asia-Pacific Journal of Chemical Engineering 5(1): 73-82.

[5] Chang, C.-Y., Chang, J.-S., Lin, Y.-W., Erdei, L., Vigneswaran, S. (2006): Quantification of air stripping and biodegradation of organic removal in acrylonitrile-butadiene-styrene (ABS) industry wastewater during submerged membrane bioreactor operation. Desalination 191(1-3): 162-168.

[6] Elawwad, A., Zaghloul, M., Abdel-Halim, H. (2017): Simulation of municipal-industrial full scale WWTP in an arid climate by application of ASM3. - Journal of Water Reuse and Desalination 7(1): 37-44.

[7] Gao, F., Nan, J., Li, S., Wang, Y. (2018): Modeling and simulation of a biological process for treating different COD: $\mathrm{N}$ ratio wastewater using an extended ASM1 model. Chemical Engineering Journal 332: 671-681.

[8] Gujer, W., Henze, M., Mino, T., Matsuo, T., Wentzel, M., Marais, G. (1995): The activated sludge model No. 2: biological phosphorus removal. - Water Science and Technology 31(2): 1-11.

[9] Gujer, W., Henze, M., Mino, T., Van Loosdrecht, M. (1999): Activated sludge model no. 3. - Water Science and Technology 39(1): 183-193.

[10] Henze, M., Gujer, W., Mino, T., van Loosdrecht, M. C. (2000): Activated sludge models ASM1, ASM2, ASM2d and ASM3. - IWA Publishing, London.

[11] Lee, Y., Cho, J., Seo, Y., Lee, J. W., Ahn, K.-H. (2002): Modeling of submerged membrane bioreactor process for wastewater treatment. - Desalination 146(1-3): 451457.

[12] Li, F., Behrendt, J., Wichmann, K., Otterpohl, R. (2009): Evaluation of factors influencing soluble microbial product in submerged MBR through hybrid ASM model. Frontiers of Environmental Science \& Engineering in China 3(2): 226-235.

[13] Liwarska-Bizukojc, E., Olejnik, D., Biernacki, R., Ledakowicz, S. (2011): Calibration of a complex activated sludge model for the full-scale wastewater treatment plant. Bioprocess and Biosystems Engineering 34(6): 659-670.

[14] Mannina, G., Di Bella, G., Viviani, G. (2011): An integrated model for biological and physical process simulation in membrane bioreactors (MBRs). - Journal of Membrane Science 376(1-2): 56-69.

[15] Ng, A. N., Kim, A. S. (2007): A mini-review of modeling studies on membrane bioreactor (MBR) treatment for municipal wastewaters. - Desalination 212(1-3): 261281.

[16] Song, Y.-j., Xie, Y.-b., Yudianto, D. (2012): Extended activated sludge model no. 1 (ASM1) for simulating biodegradation process using bacterial technology. - Water Science and Engineering 5(3): 278-290.

[17] Wang, H.-C., Cheng, H.-Y., Wang, S.-S., Cui, D., Han, J.-L., Hu, Y.-P., Su, S.-G., Wang, A.-J. (2016): Efficient treatment of azo dye containing wastewater in a hybrid acidogenic bioreactor stimulated by biocatalyzed electrolysis. - Journal of Environmental Sciences 39: 198-207.

[18] Wu, X., Yang, Y., Wu, G., Mao, J., Zhou, T. (2016): Simulation and optimization of a coking wastewater biological treatment process by activated sludge models (ASM). Journal of Environmental Management 165: 235-242.

[19] Zhou, M., Gong, J., Yang, C., Pu, W. (2013): Simulation of the performance of aerobic granular sludge SBR using modified ASM3 model. - Bioresource Technology 127: 473481. 